\title{
A Conversation Between Markus Schwaiger and Johannes Czernin
}

\author{
Markus Schwaiger $^{1}$ and Johannes Czernin ${ }^{2}$
}

${ }^{I}$ Technische Universität München, Munich, Germany; and ${ }^{2}$ David Geffen School of Medicine at UCLA, Los Angeles, California

$\mathbf{M}$ arkus Schwaiger has been Medical Director at the university hospital "Klinikum rechts der Isar" of the Technical University of Munich (TUM) since 2016. From 1993 to 2017 he was Director of the Clinic and Polyclinic of Nuclear Medicine. His main area of research is the use of multimodal imaging to visualize and quantify biologic processes. His research involves the use of PET in cardiology and oncology. He is Director of the German Research Foundation's Collaborative Research Center 824, which deals with molecular imaging for selecting and monitoring oncologic therapies. Diagnosis and treatment of thyroid endocrine and neuroendocrine diseases are also of special interest. Dr. Schwaiger studied medicine at Freie Universität Berlin and Freiburg University. His career as a doctor and researcher has taken him to the University of California Los Angeles (UCLA) School of Medicine and the University of Michigan (Ann Arbor), as well as other academic sites. He is a member of the Bavarian Academy of Sciences and the Deutsche Akademie der Naturforscher Leopoldina. He has an honorary doctorate from the University of Varna, Bulgaria.

Dr. Czernin: I want to start out with a bit of your biography. You studied medicine at the Freie Universität Berlin in the 1960s. That was at a time when many people would not have focused on studying but instead were on the streets demonstrating. What was the climate at the university at that time?

Dr. Schwaiger: It was definitely a climate of change. The German so-called "68 movement" was a primarily student-driven reaction against the authoritarian structures of German society in general and in particular against the rigid structures at universities. Discussions focused on liberation from traditional, hierarchic structures, following mostly left-wing ideologies. This political reorientation was part of the German recovery process from the Hitler regime and World War II. At the university level, students petitioned to be part of academic decision-making bodies defining areas and content of curricula. It was a very interesting and challenging time for me personally, coming from a well-preserved bourgeois environment in Munich. We all needed to define our own political position in very unstable times. Retrospectively, it is important to note that the student protests started off many reforms in German society and universities. Maybe the students were a little bit too loud at the time, but the results had significant impacts on democratic processes in Germany.

Dr. Czernin: What happened after medical school?

Dr. Schwaiger: I moved back to Munich, where I was born. I did my early clinical training there and completed my doctoral thesis on vector electrocardiography. During that time, I started

COPYRIGHT @ 2019 by the Society of Nuclear Medicine and Molecular Imaging. my research career with an international stipend, which allowed me to spend 1 year in Cincinnati $(\mathrm{OH})$ working in physiology. This 1-year fellowship initiated my interest in cardiovascular sciences, because I studied the vascular effects of histamine in the mesenteric circulation. After returning to Germany I started out as a cardiac surgeon-but not for long. I switched over to cardiology and began a combined program of internal medicine and cardiology at the German Heart Center in Munich.

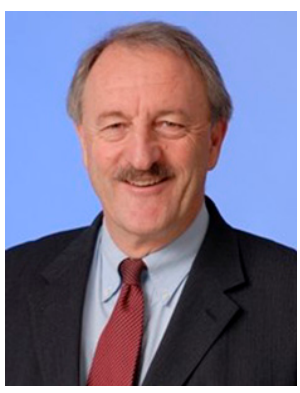
MD
Markus Schwaiger,

Dr. Czernin: And this is when your research career started?

Dr. Schwaiger: I started in the area of nuclear cardiology with radionuclide ventriculography (RNV) and myocardial scintigraphy. At that time, RNV was the only method to measure cardiac function noninvasively, so as a young cardiologist I was quite excited. Subsequently, the role of myocardial metabolism attracted my attention, because we became interested in learning how the mechanical performance of the heart was supported by energetics. I was told that there was a new "machine" in the United States that allowed noninvasive measurement of cardiac metabolism. This was the beginning of cardiac PET. I went to UCLA to visit Heinz Schelbert and became extremely excited about emerging research possibilities using metabolic imaging with ${ }^{18} \mathrm{~F}-\mathrm{FDG}$ and ${ }^{11} \mathrm{C}$-palmitate. I must admit I was even more enthusiastic about the idea of living in Westwood near Santa Monica. Retrospectively, my decision to move to LA turned out to be a very positive step, because, as you know, UCLA has been an outstanding environment for many young German cardiologists. I had access to new resources we did not have at home. In addition, the academic freedom at American universities, along with the support and excellent training provided by leaders in the field, represented an ideal start for my research in cardiovascular imaging.

Dr. Czernin: And then you did all the pivotal early viability studies with Heinz?

Dr. Schwaiger: I learned to do animal experiments in Cincinnati, because we worked on the functional characterization of histamine receptors in dog models. So I was quite familiar with experimental models and enjoyed combining preclinical with clinical research. When I started at UCLA, I wanted to use PET imaging to characterize experimental models of ischemia and reperfusion. This was the time when recanalization of the coronary arteries in the setting of acute myocardial infarction became the favored strategy to rescue myocardial tissue. The pioneering research of Dr. William Ganz in this area at Cedars-Sinai (Los Angeles, CA) inspired me to follow this direction. We hypothesized that PET imaging would be useful to predict myocardial recovery after transient ischemia. Indeed, we observed that increased ${ }^{18} \mathrm{~F}-\mathrm{FDG}$ uptake in 
ischemic areas was a signal of viability, as evidenced by subsequent functional recovery. This experimental work was part of a larger research program at UCLA that defined the role of PET in clinical identification of viable myocardium in the setting of advanced ischemic heart disease.

Dr. Czernin: After a long and very fruitful collaboration with Heinz Schelbert you left UCLA in 1987 and moved to Michigan.

Dr. Schwaiger: This was a difficult decision, because I really enjoyed UCLA and I had just finished my cardiology fellowship there. I was offered a position in the Division of Cardiology and Nuclear Medicine. But at the same time I felt that it might be better for me to start my own independent research group. At this time, Michigan excelled with a very prominent cardiology program headed by Dr. Bertram Pitt. Dr. Eric Topol, Dr. Cindy Grines, and many others were recruited to focus on innovative ways to treat acute myocardial infarction. This was scientifically a very exciting time, because cardiology changed from a conservative to a very "aggressive" discipline based on intervention in treatment of coronary artery disease. We were all excited to be part of the rapid changes leading to interventional cardiology. Nuclear cardiology was in many aspects an important part of this process.

Dr. Czernin: You stayed there for 6 years and were then offered the chair position at the Department of Nuclear Medicine at TUM.

Dr. Schwaiger: I had the opportunity to go back to Munich. After many discussions, we decided as a family to return to Germany. I was very optimistic about taking all of my very positive experience in the United States back to Europe.

Dr. Czernin: This leads us to the focal point of the discussion that I would like to have with you. In Munich, you served as chair, then became dean of the medical school in 2002 and medical director of environment in which everyone must have insurance coverage. The "hybrid" German system also includes private insurance for high-income groups with broader coverage. The bottom line is that everybody has free choice of physicians and access to all aspects of the German health care system without restrictions. On the other hand, German health care providers face the problem that services are "capitated." This means that physicians and hospitals work within predefined budgets that are negotiated with insurance companies. The result of this capitation is that the cost of German health care is about half that in the United States. The system is efficient, but resources are restricted, especially for academic institutions. For example, the role of clinician scientists at academic centers is much less developed than in the United States. At German institutions research is usually done after hours, because physicians are primarily engaged in clinical services. In addition, structures in German academic institutions are quite hierarchic. Each department is directed by 1 chair, and everyone else serves this chair. This leads to a much more vertical organization than in the United States. The advantage is, I have to admit, that one has a high degree of freedom when at the top of this hierarchy. In recent years, several changes have been made to adapt the German structure to the increasing need for protected research time.

Overall, I think both the U.S. and European systems have their strengths and limitations as far as research is concerned. However, I am convinced that the United States provides a more attractive academic environment, whereas Europe excels in very efficient overall health care for most members of society.

Dr. Czernin: When you talk about capitation in Germany what do you mean? The patient has insurance, and he or she has to pay into this system.

\section{"Overall, I think both the U.S. and European systems have their strengths and limitations as far as research is concerned. However, I am convinced that the United States provides a more attractive academic environment, whereas Europe excels in very efficient overall health care for most members of society."}

the hospital in 2017. This is the time lapse version of your career in Munich. You got to know 2 different health care systems intimately: the one that we have in the United States versus the European system that is often characterized as "socialistic" in the United States. In your view, what are the advantages and disadvantages of both systems? In particular I want to ask you this question because you are now in a leadership position in administration. which I think gives you an entirely different view of how health care can and should be done.

Dr. Schwaiger: This can only be answered by comparing European with American histories, leading to different models of health care systems. The American concept of a "fee for service" system resulted in excellent medical care at leading academic institutions. This is what I appreciated as an academically oriented physician, because there was no shortage of resources. At UCLA, there was a superb research infrastructure matched by large departments serving most medical subspecialties. What I experienced to be very attractive about this system was the opportunity to do clinical work as well as research. However, these almost luxurious conditions are somewhat offset by the societal point of view. The entrepreneurial health care structure represents a very expensive system. Because medical insurance coverage is limited, the advantages of this system are accessible to only part of society. Underprivileged members of the society have only limited access. In contrast, Germany has a relatively "social" health care system, which works in an
Dr. Schwaiger: When I say "capitated" I am not talking about an individual patient. I am talking about services provided by hospitals and physicians. Each year a hospital is assigned a budget and must predict how many patients will likely be seen and how many services will be provided. If the numbers of patients exceed the agreed-on limit, the hospitals and physicians do not receive $100 \%$ reimbursement for those patients—only a certain percentage. That means that physicians are primarily paid for a fixed budget and are not expected to exceed the predicted patient numbers or agreed-on number of services.

Dr. Czernin: That is kind of the dream world for utilization review boards: where you have an almost natural system that limits what can be spent-and if you overspend, it costs you. What I always find fascinating is that, even with the so-called restrictions that you have in the supply of health care, overall survival is still better than in the United States. Part of that is, of course, attributable to the socioeconomic structure here in the United States.

Dr. Schwaiger: There are important differences between Germany and the United States. Germany is a much smaller country with a much more homogeneous population. In addition, there is a long tradition of mandatory insurance coverage. The German system is not a "public health care system" like that in Great Britain. It is a health care system financed by insurance carriers, competing with 
each other for good services. However, the extent of services is defined by a central agency operated and financed by the Ministry of Health. For example, this agency defines reimbursable indications for PET. In contrast to most countries, PET is only covered for a few indications as an outpatient service. Use of PET is controlled by primarily allowing hospitals to perform an agreed-on number of PET scans. The government is very concerned that expensive diagnostic methods are overutilized, primarily in the outpatient setting. This has led to a much more restrictive regulation of PET as compared with other countries in Europe and the United States.

Dr. Czernin: There's a second aspect that I think is sometimes forgotten here in the discussion, and that is that every citizen, of course, can purchase his or her own extra private insurance. What percentage of people do that-10\% to $20 \%$ ?

Dr. Schwaiger: Fifteen percent to $20 \%$. But you must have a certain minimal income to be eligible for private insurance. In western Germany, it is about $15 \%$ to $20 \%$, in east Germany it is less than $10 \%$.

Dr. Czernin: There is another misconception in the United States about the European health system. It is often believed here that health care is free in Europe. And I think it's important to explain to the readers that, of course, health care is not free.

Dr. Schwaiger: This is not that different compared with the United States. However, the cost of insurance is split between employer and employee. The providers bill insurance companies, which cover the health care costs.

Dr. Czernin: I just wanted to make sure that we understand that it is not free.

Dr. Schwaiger: Not at all. We do not have a "nationalized health care system" like in Great Britain.

Dr. Czernin: Despite the high clinical workload you described before that leaves residents and fellows as well as faculty much less time for research, you created a highly successful research environment. How is that managed when you cannot really pay people for that?

Dr. Schwaiger: The situation has changed in Germany during the past 20 years, because grant support has increased substantially. Currently, it is easier to obtain grant support in Germany than in the United States. In Germany, the funding rate is between $20 \%$ and $30 \%$. As I understand it, the funding rate in the United States is about $10 \%$. Research funding is also distributed throughout the European Union, and especially the European Research Council (ERC) represents a very important agency supporting individual scientists throughout Europe. Typical ERC grants amount to $€ 2-3$ million over a time period of 5 years. So, yes, it is more an issue of research time and resources and less of a funding issue. Still, it remains difficult to combine research with a clinical career, mainly because of a limited number of professor positions available at German academic medical centers.

Dr. Czernin: The improved funding is good news for now. But you were able to create a successful research program before this infrastructure was created.

Dr. Schwaiger: The only way I could do it was because I was able to raise grant money. In addition, I always had about $20 \%$ to $30 \%$ nonmedical scientists in our research group. Nuclear medicine allows the recruitment of nonmedical research personnel because of its tradition in medical physics and radiochemistry. This gave me the freedom to develop an interdisciplinary group of scientists. I have been quite privileged to work with very talented physicists and radiochemists during recent years.

Dr. Czernin: You raised funds through foundations?

Dr. Schwaiger: Yes. Foundations and donor money exist, and at Bavarian universities there is basic support that can actually be invested in research personnel and infrastructure.
Dr. Czernin: There must be something different about the people who enter the field in Germany versus the United States. Because I think one must have a very special drive to work until 10:00 or 11:00 at night and really develop this keen interest in research.

Dr. Schwaiger: If you look at high achievers in the United States, they work pretty hard, too. I think you have more resources at academic institutions in the United States, and, in most instances, you can decide how much time you want to spend in research and how much time in clinical work. We are fighting right now for a "clinician scientist program," which allows up to 1 year of protected research time during training as a specialist. However, this time is currently not recognized for board certification. So, as I recall, in the United States you can do 1 year of research fellowship during training. A similar program is just starting in Germany now. We want research fellowships to be considered part of medical training.

Dr. Czernin: So here you have 4 months of research time during the 3-year training.

Dr. Schwaiger: This is very much needed in Germany, especially in times when translational research is growing. I see increasing challenges to match good clinical training with the growing demand for competitive research in medicine.

Dr. Czernin: Maybe there's another argument for why you have these really ambitious people. In Germany you have to become the chief to really be free. You can only become the chief if you have the track record that shows that you are qualified academically.

Dr. Schwaiger: I recently attended a meeting of German academic medical centers. One intensely discussed question was how we could become internationally more competitive. There was consensus that we have to develop a career path for young physicians to support their pathway to independent investigator status by providing time and resources. It would be an effective means to overcome the existing hierarchic system with only few positions at the top of the organization. For the younger generation of physicians, it is just not attractive enough if a limited number of leadership positions are available. There is increasing awareness about needed changes at university hospitals to attract and keep the best people in academia.

Dr. Czernin: So when you narrow this discussion down a little bit to nuclear medicine, there is actually no question that Germany, The Netherlands, Italy, and, of course, the Scandinavian countries are highly competitive, because most of the new developments really come from Europe. So it is an interesting paradox that great successes have come from an environment in which it is really not so easy.

Dr. Schwaiger: Additional factors reflect the role of nuclear medicine in Europe. Nuclear medicine is an independent subspecialty in Germany and most European countries. So it is an entity that was always considered as innovative and very technically oriented. Nuclear medicine was driven not only by physicians but also by physicists and chemists. Nuclear medicine was initially placed in internal medicine and endocrinology. Because of very strict radiation protection laws in Germany, it always had its own inpatient clinical service in hospitals. So it is considered an independent subspecialty like internal medicine or surgery, serving not only diagnostic but also therapeutic services. This is in contrast to radiology, which has no inpatient resources of its own.

Dr. Czernin: I also think that the business model makes a big difference, again because you do not have to generate profits. In the United States we are supposed to have, as a worst-case scenario, a balanced budget-and usually are supposed to generate surplus. And this is difficult to do with nuclear medicine, because it is not a volume-based business. 
Dr. Schwaiger: You would be surprised! With increasing reimbursement for radionuclide therapies nuclear medicine is one of the more profitable units at our hospital. Not only thyroid and neuroendocrine therapies but also prostate therapy are currently well reimbursed. The emerging role of theranostics will definitely change the role of nuclear medicine in oncology. It remains to be determined whether nuclear medicine will be able to maintain leadership in the application of radionuclide therapy. This leadership can only be secured by continuing innovation.

Dr. Czernin: So that is what I was getting at. There is, of course, a great new opportunity in the United States, because theranostics can really change the business model for nuclear medicine. This may change the way nuclear medicine is managed in the United States. We suddenly have more applicants for residency positions, for example. So something positive is happening.

Let me get back to your career. You went from leading very small units to increasingly larger units-as chair of a department to being dean of a school of medicine and now leading an entire hospital as medical director. How did that change your view of leadership? How do structures within the larger system work best, independently or in concert with other units? How do you best foster a system in which people have incentives to become successful?

Dr. Schwaiger: Yes, it is much more difficult to reach individual people when you increase your responsibilities. Time becomes much more valuable. Of course, when you have a group of 20 people, then it is much easier to interact personally. You have much more direct contact, and you can motivate people more easily. When you are moving upward, the most challenging aspect is how to communicate your ideas. You have to be much more formal and use measures that motivate indirectly. This means you need to have various levels of supporters to get your "message" heard. This just requires a different way of interacting. Overall, though, I believe that the incentives are pretty much the same. Individuals want to be recognized as an important part of an organization and expect you to value their contributions.

Dr. Czernin: This series is called Discussions with Leaders. How would you define leadership?

Dr. Schwaiger: It is most important to have a defined strategy in order to lead an organization. The second step is to convince your staff and colleagues to follow your direction. In most cases, this cannot be achieved with a top-down strategy that forces people to follow you. In my opinion, the most successful approach is if you motivate your staff to voluntarily take the direction in which you want them to go. Currently, I put most of my energy into convincing people that a change of old-fashioned processes will contribute to overall better success for our hospital. The introduction of "digital medicine" is a motor and motivation for change. One of my major goals in Germany is to decrease hierarchic steepness in our system. Second, I am focusing on measures to overcome the rigid organization in subspecialties. I try to support structures leading to more interdisciplinarity and interprofessionality. As we are part of the TUM, we have the opportunity to import many ideas from engineers, physicists, and computer scientists into the daily work of our hospital.

Coming back to my background in nuclear medicine, I guess the success of nuclear medicine is a reflection of interdisciplinary research. Without chemists, radiochemists, physicists, and others, nuclear medicine would never be where it is right now. Many aspects of progress in biology were and are dependent on the introduction of new technologies. Creating an open interdisciplinary culture is one of the goals of the TUM as a measure of scientific competitiveness.

Dr. Czernin: Do you still believe in department structures?

Dr. Schwaiger: Yes, I do. But I also believe that we have to overcome some of the limitations created by the existence of too many small subunits or sections. Often, such subunits are driven by self-interest, and these self-centered strategies must be overcome. The challenge is to find the right balance so that people are happy and can identify with their own areas. On the other hand, they need to recognize that they are part of a large organization. In my opinion, this organizational balance is the key to creating ideal structures at academic medical centers.

Dr. Czernin: So if I understand you correctly, you are for collaboration and integration. Barriers that are unnecessary should be removed. But you wouldn't want to close small entities. This is bringing us back to nuclear medicine: you mentioned chemists, radiochemists, biologists, and physicists who work in nuclear medicine. I think it's unfortunate and counterproductive if these individuals are administratively under, for example, a radiology department.

Dr. Schwaiger: I agree with you. Nuclear medicine or molecular imaging has its own culture, which we need to preserve and exploit. Of course, we also have to make sure that we do not have to buy 3 PET/CT units, 2 for radiology and 1 for molecular imaging. The overriding strategy must be that we support the most efficient patient services. From an organizational point of view, nuclear medicine and radiology have to deliver an integrated clinical service. On the other hand, they should remain independent in research and development.

Dr. Czernin: Markus, what are your plans for the next 5 years?

Dr. Schwaiger: I will probably be in my current position for another 3 years. During this time, I hope to develop more interdisciplinary strategies with our colleagues in engineering. For example, I am excited about introducing robotics into clinical care and using imaging to guide these robots. I see a future that includes minimally invasive interventions, coupled with precise imaging procedures that define various characteristics of the body, including "molecular sensing." I see the role of imaging as an advanced support system for interventions. The emerging new techniques in computer science and data analysis (artificial intelligence, machine learning) allow us to perform a new kind of medicine that I would like to stimulate in our center. We have just founded a big center for robotic medicine at the TUM combining robotics and sensing.

Dr. Czernin: Do you also focus on artificial intelligence?

Dr. Schwaiger: I don't use this word because I think it's quite overused. But I believe that there are new methods to handle large datasets in a very condensed time frame. Yes, artificial intelligence will change the way we apply our technologies. Especially, imaging and artificial intelligence will be a nice and tight package. One emerging idea is to generate an "electronic twin" for a given patient. We could integrate all the available information and then use this twin to plan interventions and predict response to therapy. Knowing the genetic and structural makeup of a specific patient, you may be able to test certain pharmaceutical interventions using this electronic twin. We are seeing very exciting developments in which our tools match the real and electronic worlds. I am convinced we will find useful applications for this match.

Dr. Czernin: Do you have anything else that you want to tell us?

Dr. Schwaiger: You were talking about my experience in 2 systems. What I really learned in the United States is beyond the health care system. It is the positive and very optimistic view of technologic progress. It is all about the challenge to shape the future. I learned to combine this attitude with the more critical and careful evaluation of reality that characterizes the European system. I think this mix has served me very well. So to close from my side: I feel very privileged to have been able to work in both systems, in the United States and Europe.

Dr. Czernin: Thank you very much, Markus, for your time. 